\title{
Cost-Benefit Analysis of Two-Non Identical Cold Standby System Subject To Non-Availability of Water Resulting Failure to Produce Hydroelectric Power and Failure Due To High Acoustics
}

\author{
Ashok Kumar Saini \\ Associate Professor, Department of Mathematics, B.L.J.S. College, Tosham (Bhiwani), Haryana, India
}

\begin{abstract}
India was the 7th largest producer of hydroelectric power in 2008 after Norway: 114 TWh and 3.5\% the world total in 2008. The potential for hydroelectric power in India is one of the greatest in the world. India is endowed with economically exploitable and viable hydro potential assessed to be about $84,000 \mathrm{MW}$ at $60 \%$ load factor. In addition, 6,780 MW in terms of installed capacity from Small, Mini, and Micro Hydel schemes have been assessed. Also, 56 sites for pumped storage schemes with an aggregate installed capacity of 94,000 MW have been identified. It is the most widely used form of renewable energy. India is blessed with immense amount of hydro-electric potential and ranks 5 th in terms of exploitable hydro-potential on global scenario.
\end{abstract}

The present installed capacity is approximately $\mathbf{3 9 , 7 8 8 . 4 0} \mathbf{~ M W}$ which is $17.39 \%$ of total electricity generation in India. The public sector has a predominant share of $97 \%$ in this sector. Water plays an important and pivotal role in producing hydroelectric power. Non-availability of water results failure to produce hydroelectric power. Reliability is a measure of how well a system performs or meets its design requirements. It is hence the prime concern of all scientists and engineers engaged in developing such a system.. In this paper we have taken two types of failures (1) FNAWnon-availability of water resulting failure to produce Hydroelectric Power (2) FHA-failure due to High acoustics When the main unit fails due to High Acoustics then cold standby system becomes operative. High acoustics cannot occur simultaneously in both the units and after failure the unit undergoes very costly repair facility immediately. Applying the regenerative point technique with renewal process theory the various reliability parameters MTSF, Availability, Busy period, Benefit-Function analysis have been evaluated.

KEYWORDS: Cold Standby, FNAW- non-availability of water resulting failure to produce Hydroelectric Power, FHA-failure due to High acoustics, first come first serve, MTSF, Availability, Busy period, Cost-Benefit analysis

\section{INTRODUCTION}

Stochastic behavior of systems operating under changing environments has widely been studied. . Dhillon, B.S. and Natesan, J. (1983) studied an outdoor power systems in fluctuating environment . Kan Cheng 1985) has studied reliability analysis of a system in a randomly changing environment. Jinhua Cao (1989) has studied a man machine system operating under changing environment subject to a Markov process with two states. The change in operating conditions viz. fluctuations of voltage, corrosive atmosphere, very low gravity etc. may make a system completely inoperative. Severe environmental conditions can make the actual mission duration longer than the ideal mission duration. In this paper we have taken two types of failures (1)FNAW- failure due to non-availability of water resulting failure to produce Hydroelectric Power (2) FHA-failure due to High acoustics. When the main operative unit fails due to High acoustics-FHA then cold standby system becomes operative. High acoustics cannot occur simultaneously in both the units and after failure the unit undergoes repair facility of very high cost in case of FHAfailure due to High acoustics immediately. Failure due to non-availability of water resulting failure to produce Hydroelectric power may be destructive. The repair is done on the basis of first fail first repaired. 


\title{
International Journal of Innovative Research in Science, Engineering and Technology
}

(An ISO 3297: 2007 Certified Organization)

\author{
Vol. 3, Issue 10, October 2014
}

\section{MATERIALS AND METHODS}

A random phenomenon arising through a process which developed in time in a manner controlled by probabilistic laws is called stochastic process. It is called Markovian if the future development is completely determined by the present state and is independent of the way in which state has been achieved. Mathematically, for

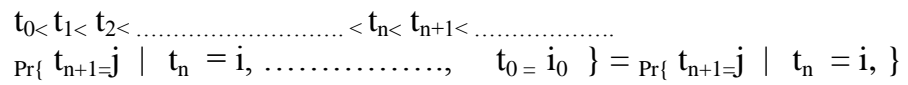

where $t_{n}$ is the state of the process at the nth transition $n=0,1,2, \ldots \ldots \ldots \ldots$.

A time point at which the system history prior to the time point, is irrelevant to the system conditions is called regenerative point . A process in which each point is a regenerative point is called a regenerative process.

Let $\mathrm{T}_{0}, \mathrm{~T}_{1}, \mathrm{~T}_{2}, \ldots \ldots \ldots \ldots \ldots \ldots \ldots$......... denote the epochs at which the system enters any state $\mathrm{i}$ belonging to set of regenerative states . Let $Z_{n}$ denote the state visited at epoch $T_{n}+$, i.e., just after the transition at $T_{n}$. Then $\left\{Z_{n}, T_{n}\right\}$ is a Markov renewal process. We have applied the regenerative point technique with renewal process theory.

\section{ASSUMPTIONS}

1. $\mathrm{F}_{1}(\mathrm{t})$ and $\mathrm{F}_{2}(\mathrm{t})$ are general failure time distributions due to non-availability of water resulting failure to produce Hydroelectric power and High acoustics. The repair is of two types -Type -I, Type-II with repair time distributions as $\mathrm{G}_{1}(\mathrm{t})$ and $\mathrm{G}_{2}(\mathrm{t})$ respectively .

2. The High acoustics are non-instantaneous and it cannot come simultaneously in both the units.

3. Whenever the acoustics occur within specified limit of the unit, it works as normal as before . But as soon as there occur High acoustics of magnitude beyond specified limit of the unit the operation of the unit stops automatically.

4. The repair starts immediately after the High acoustics of beyond specified limit of the unit are over and works on the principle first fail first repaired basis.

5. The repair facility does no damage to the units and after repair units are as good as new.

6. The switches are perfect and instantaneous.

7. All random variables are mutually independent.

8. When both the units fail, we give priority to operative unit for repair.

9. Repairs are perfect and failure of a unit is detected immediately and perfectly.

10. The system is down when both the units are non-operative.

\section{SYMBOLS FOR STATES OF THE SYSTEM}

$F_{1}(t)$ and $F_{2}(t)$ are the failure time distribution due to non-availability of water resulting failure to produce Hydroelectric power and failure due to High acoustics respectively

$\mathrm{G}_{1}(\mathrm{t}), \mathrm{G}_{2}(\mathrm{t})$ - repair time distribution Type -I, Type-II due to non-availability of water resulting failure to produce hydroelectric power and failure due to High acoustics respectively

\section{SUPERSCRIPTS O, CS, FNAW, FHA}

Operative, Cold Standby, Failure due to non-availability of water resulting failure to produce hydroelectric power, failure due to High acoustics respectively

SUBSCRIPTS nawf, nhaf, haf ur, wr, uR

Non-availability of water resulting failure to produce hydroelectric power, No High acoustics failure, High acoustics failure, under repair, waiting for repair, under repair continued from previous state respectively

Up states $-0,1,2 ; \quad$ Down states $-3,4 ; \quad$ regeneration point $-0,1,2$

\section{Notations}

$\mathrm{M}_{\mathrm{i}}(\mathrm{t})$ System having started from state $\mathrm{I}$ is up at time $\mathrm{t}$ without visiting any other regenerative state

$\mathrm{A}_{\mathrm{i}}(\mathrm{t})$ state is up state as instant $\mathrm{t}$

$R_{i}(t)$ System having started from state $I$ is busy for repair at time $t$ without visiting any other regenerative state.

$B_{i}(t)$ The server is busy for repair at time $t$.

$\mathrm{H}_{\mathrm{i}}(\mathrm{t})$ Expected number of visits by the server for repairing given that the system initially starts from regenerative state $\mathrm{i}$ 


\section{IJIRSET \\ International Journal of Innovative Research in Science, Engineering and Technology}

ISSN: 2319-8753

(An ISO 3297: 2007 Certified Organization)

Vol. 3, Issue 10, October 2014

By High acoustics we mean High acoustics beyond the specified limit

\section{STATES OF THE SYSTEM}

$\mathbf{0}\left(\mathbf{O}_{\text {nhaf }}, \mathbf{C S}_{\text {nhaf }}\right)$ One unit is operative and the other unit is cold standby and there are no High acoustics failure in both the units.

1(SOFHA haf, ur, $\left.\mathbf{O}_{\text {nhaf }}\right)$ The operating unit fails due to High acoustics and is under repair immediately of very costly Type- I and standby unit starts operating with no High acoustics.

2(FNAW nhaf, nawf, ur, $\mathbf{O}_{\text {nhaf }}$ ) The operative unit fails to produce hydroelectric power due to FNAW resulting from nonavailability of water and undergoes repair of type II and the standby unit becomes operative with no High acoustics.

3(FHA haf,uR $_{\text {, FNAW }}$ nhaf ,naw,wr) The first unit fails due to High acoustics and under very costly Type-! repair is continued from state 1 and the other unit fails to produce hydroelectric power due to FNAW resulting from nonavailability of water and is waiting for repair of Type -II .

4(FHA haf,uR, $\mathbf{F H A}_{\text {haf,wr }}$ ) The one unit fails due to High acoustics is continues under repair of very costly Type - I from state 1 and the other unit also fails due to High acoustics. is waiting for repair of very costly Type- I.

5(FNAW nhaf, nawf, uR, FHA $_{\text {haf, wr }}$ ) The operating unit fails to produce hydroelectric power due to non-availability of water (FNAW mode) and under repair of Type - II continues from the state 2 and the other unit fails due to High acoustics is waiting for repair of very costly Type- I.

6(FNAW nhaf,nawf,uR , FNAW nhaf,naw,wr) The operative unit fails to produce hydroelectric power due to FNAW

resulting from non- availability of water and under repair continues from state 2 of Type -II and the other unit is also failed to produce hydroelectric power due to FNAW resulting from non-availability of water and is waiting for repair of Type-II and there is no High acoustics.

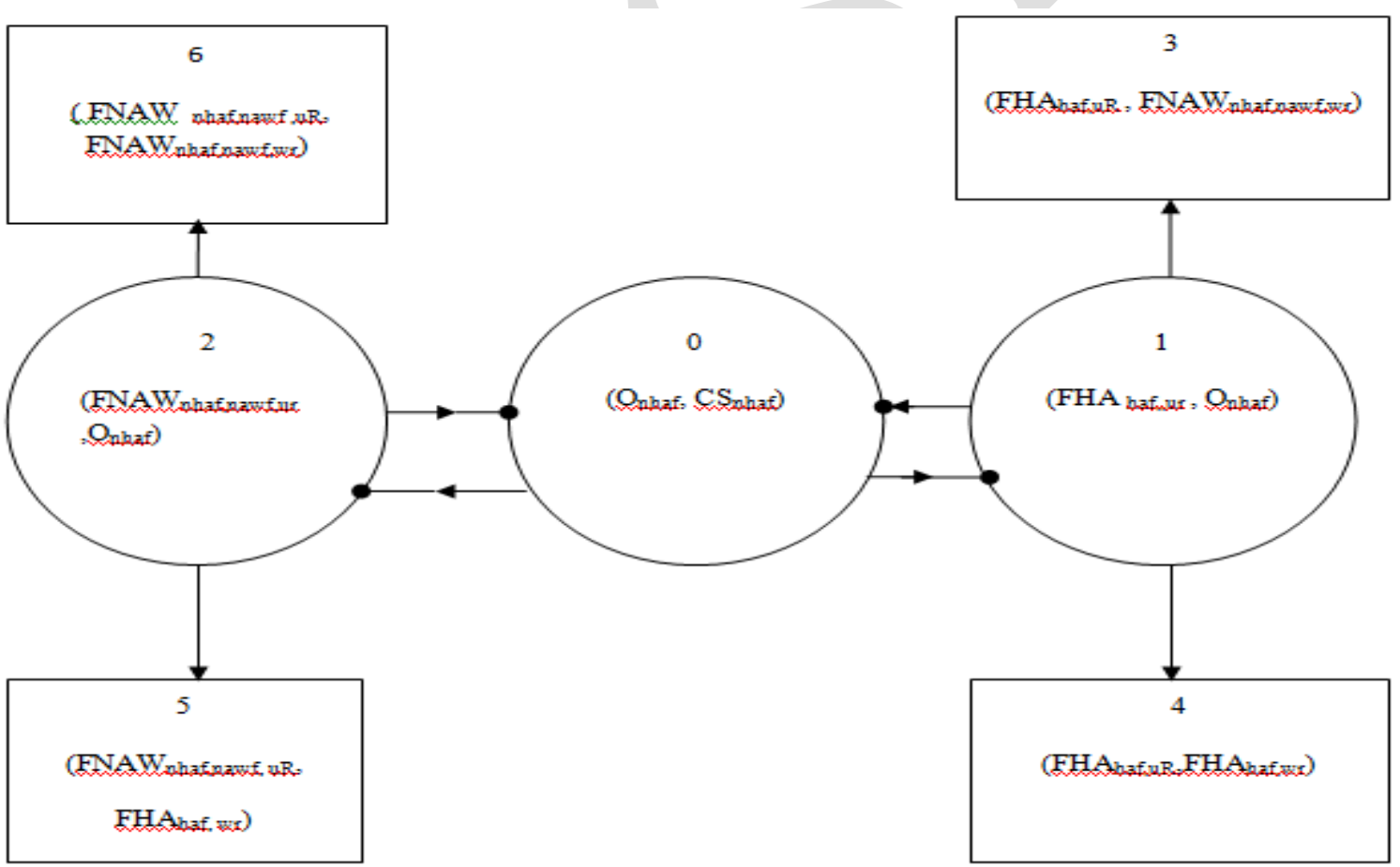

Fig.1 the State Transition Diagram

- Regeneration point -states $0,1,2$

Up State

Down State 


\section{ISSN: 2319-8753}

IJIRSET

\section{International Journal of Innovative Research in Science, Engineering and Technology}

(An ISO 3297: 2007 Certified Organization)

\section{Vol. 3, Issue 10, October 2014}

\section{TRANSITION PROBABILITIES}

Simple probabilistic considerations yield the following expressions :

$$
\begin{aligned}
& \mathrm{p}_{01}=\int_{0}^{\infty} \bar{F}_{\mathbf{2}}(t) d F_{1}(t), \quad \mathrm{p}_{02}=\int_{0}^{\infty} \bar{F}_{1}(t) d F_{\mathbf{2}}(t) \\
& \mathrm{p}_{10}=\int_{0}^{\infty} \bar{F}_{\mathbf{2}}(t) d G_{1}(t), \quad \mathrm{p}_{13}=\mathrm{p}_{11}{ }^{(3)}=\mathrm{p}_{11}{ }^{(4)}=\int_{0}^{\infty} \bar{G}_{1}(t) d F_{\mathbf{2}}(t) \\
& \mathrm{p}_{25}=\mathrm{p}_{22}{ }^{(5)}=\mathrm{p}_{22}{ }^{\left({ }^{(}\right)}=\int_{0}^{\infty} \bar{G}_{\mathbf{2}}(t) d F_{1}(t) \\
& \text { clearly } \\
& \mathrm{p}_{01}+\mathrm{p}_{02}=1, \quad \mathrm{p}_{10}+\mathrm{p}_{13}=\left(\mathrm{p}_{11}{ }^{(3)}\right)+\mathrm{p}_{14}=\left(\mathrm{p}_{11}{ }^{(4)}\right)=1, \mathrm{p}_{20}+\mathrm{p}_{25}=\left(\mathrm{p}_{22}{ }^{(5)}\right)+\mathrm{p}_{26}=\left(\mathrm{p}_{22}{ }^{(6)}\right)=1
\end{aligned}
$$

And mean sojourn time are

$$
\mu_{0}=\mathrm{E}(\mathrm{T})=\int_{0}^{\infty} P[T>t] d t
$$

\section{MEAN TIME TO SYSTEM FAILURE}

$\emptyset_{0}(\mathrm{t})=\mathrm{Q}_{01}(\mathrm{t})[\mathrm{s}] \varnothing_{1}(\mathrm{t})+\mathrm{Q}_{02}(\mathrm{t})[\mathrm{s}] \varnothing_{2}(\mathrm{t})$

$\varnothing_{1}(\mathrm{t})=\mathrm{Q}_{10}(\mathrm{t})[\mathrm{s}] \varnothing_{0}(\mathrm{t})+\mathrm{Q}_{13}(\mathrm{t})+\mathrm{Q}_{14}(\mathrm{t})$

$\emptyset_{2}(\mathrm{t})=\mathrm{Q}_{20}(\mathrm{t})[\mathrm{s}] \varnothing_{0}(\mathrm{t})+\mathrm{Q}_{25}(\mathrm{t})+\mathrm{Q}_{26}(\mathrm{t})$

We can regard the failed state as absorbing

Taking Laplace-Stiljes transform of eq. (3-5) and solving for

$$
\emptyset_{0}{ }^{*}(\mathrm{~s})=\mathrm{N}_{1}(\mathrm{~s}) / \mathrm{D}_{1}(\mathrm{~s})
$$

where

$\mathrm{N}_{1}(\mathrm{~s})=\mathrm{Q}_{01}{ }^{*}\left[\mathrm{Q}_{13}{ }^{*}(\mathrm{~s})+\mathrm{Q}_{14}{ }^{*}(\mathrm{~s})\right]+\mathrm{Q}_{02}{ }^{*}\left[\mathrm{Q}_{25}{ }^{*}(\mathrm{~s})+\mathrm{Q}_{26}{ }^{*}(\mathrm{~s})\right]$

$\mathrm{D}_{1}(\mathrm{~s})=1-\mathrm{Q}_{01}{ }^{*} \mathrm{Q}_{10}{ }^{*}-\mathrm{Q}_{02}{ }^{*} \mathrm{Q}_{20}{ }^{*}$

Making use of relations (1) \& (2) it can be shown that $\emptyset_{0}{ }^{*}(0)=1$, which implies that $\emptyset_{0}{ }^{*}(\mathrm{t})$ is a proper distribution.

$\mathrm{MTSF}=\mathrm{E}[\mathrm{T}]=\mathrm{d} / \mathrm{ds} \emptyset_{0}{ }^{*}(\mathrm{~s}) \quad \mathrm{s}_{\mathrm{s}}=0$

$=\left(\mathrm{D}_{1}^{\prime}(0)-\mathrm{N}_{1}^{\prime}(0)\right) / \mathrm{D}_{1}(0)$

$=\left(\mu_{0}+\mathrm{p}_{01} \mu_{1}+\mathrm{p}_{02} \mu_{2}\right) /\left(1-\mathrm{p}_{01} \mathrm{p}_{10}-\mathrm{p}_{02} \mathrm{p}_{20}\right)$

where

$\mu_{0}=\mu_{01}+\mu_{02}, \mu_{1}=\mu_{10}+\mu_{13}+\mu_{14}, \quad \mu_{2}=\mu_{20}+\mu_{25}+\mu_{26}$

\section{AVAILABILITY ANALYSIS}

Let $\mathrm{M}_{\mathrm{i}}(\mathrm{t})$ be the probability of the system having started from state $\mathrm{I}$ is up at time $\mathrm{t}$ without making any other regenerative state. By probabilistic arguments, we have

The value of $M_{0}(t), M_{1}(t), M_{2}(t)$ can be found easily.

The point wise availability $\mathrm{A}_{\mathrm{i}}(\mathrm{t})$ have the following recursive relations

$\mathrm{A}_{0}(\mathrm{t})=\mathrm{M}_{0}(\mathrm{t})+\mathrm{q}_{01}(\mathrm{t})[\mathrm{c}] \mathrm{A}_{1}(\mathrm{t})+\mathrm{q}_{02}(\mathrm{t})[\mathrm{c}] \mathrm{A}_{2}(\mathrm{t})$

$\mathrm{A}_{1}(\mathrm{t})=\mathrm{M}_{1}(\mathrm{t})+\mathrm{q}_{10}(\mathrm{t})[\mathrm{c}] \mathrm{A}_{0}(\mathrm{t})+\mathrm{q}_{11}{ }^{(3)}(\mathrm{t})[\mathrm{c}] \mathrm{A}_{1}(\mathrm{t})+\mathrm{q}_{11}{ }^{(4)}(\mathrm{t})[\mathrm{c}] \mathrm{A}_{1}(\mathrm{t})$,

$\mathrm{A}_{2}(\mathrm{t})=\mathrm{M}_{2}(\mathrm{t})+\mathrm{q}_{20}(\mathrm{t})[\mathrm{c}] \mathrm{A}_{0}(\mathrm{t})+\left[\mathrm{q}_{22}{ }^{(5)}(\mathrm{t})[\mathrm{c}]+\mathrm{q}_{22}{ }^{(6)}(\mathrm{t})\right][\mathrm{c}] \mathrm{A}_{2}(\mathrm{t})$

(7-9)

Taking Laplace Transform of eq. (7-9) and solving for $\hat{A}_{0}(s)$

where

$$
\hat{A}_{0}(s) \quad=\quad \mathrm{N}_{2}(\mathrm{~s}) / \mathrm{D}_{2}(\mathrm{~s})
$$

$\mathrm{N}_{2}(\mathrm{~s})=\widehat{M}_{0}(\mathrm{~s})\left(1-\hat{q}_{11}{ }^{(3)}(\mathrm{s})-\hat{q}_{11}{ }^{(4)}(\mathrm{s})\right)\left(1-\hat{q}_{22}{ }^{(5)}(\mathrm{s})-\hat{q}_{22}{ }^{(6)}(\mathrm{s})\right)+\bar{q}_{0_{1}}(\mathrm{~s}) \widehat{M}$ 


\section{ISSN: 2319-8753}

IJIRSET

\section{International Journal of Innovative Research in Science,} Engineering and Technology

(An ISO 3297: 2007 Certified Organization)

Vol. 3, Issue 10, October 2014

$\left[1-\hat{q}_{22}{ }^{(5)}(\mathrm{s})-\hat{q}_{22}{ }^{(6)}(\mathrm{s})\right]+\hat{q}_{02}(\mathrm{~s}) \widehat{M}_{2}(\mathrm{~s})\left(1-\hat{q}_{11}{ }^{(3)}(\mathrm{s})-\hat{q}_{11}{ }^{(4)}(\mathrm{s})\right)$ $\mathrm{D}_{2}(\mathrm{~s})=\left(1-\hat{q}_{11}{ }^{(3)}(\mathrm{s})-\hat{q}_{11}{ }^{(4)}(\mathrm{s})\right)\left\{1-\hat{q}_{22}{ }^{(5)}(\mathrm{s})-\hat{q}_{22}{ }^{(6)}(\mathrm{s})\right)\left[1-\left(\hat{q}_{01}(\mathrm{~s}) \hat{q}_{10}(\mathrm{~s})\right)\left(1-\hat{q}_{11}{ }^{(3)}(\mathrm{s})-\hat{q}_{11}{ }^{(4)}(\mathrm{s})\right)\right]$

The steady state availability

$\mathrm{A}_{0}=\lim _{t \rightarrow \infty}\left[A_{0}(t)\right]=\lim _{s \rightarrow 0}\left[s \hat{A}_{0}(s)\right]=\lim _{s \rightarrow 0} \frac{s N_{2}(s)}{D_{2}(s)}$

Using L' Hospitals rule, we get

$\mathrm{A}_{0}=\lim _{s \rightarrow 0} \frac{N_{2}(s)+s N_{2}(s)}{D_{2}(s)}=\frac{N_{2}(0)}{D_{2}(0)}$

The expected up time of the system in $(0, t]$ is

$\lambda_{\mathrm{u}}(\mathrm{t})=\int_{0}^{\infty} A_{0}(z) d z \quad$ So that $\overline{\lambda_{\mathrm{u}}}(\mathrm{s})=\frac{\widehat{A}_{0}(\mathrm{~s})}{\mathrm{s}}=\frac{N_{\mathrm{z}}(S)}{S D_{\mathrm{z}}(S)}$

The expected down time of the system in $(0, \mathrm{t}]$ is

$$
\lambda_{d d}(t)=t-\lambda_{u}(t) \quad \text { So that } \overrightarrow{\lambda_{d}}(s)=\frac{1}{a^{2}}-\widehat{\lambda_{u}}(s)
$$

IX. THE EXPECTED BUSY PERIOD OF THE SERVER WHEN THERE IS FNAW-FAILURE DUE TO NON-AVAILABILITY OF WATER RESULTING NOT TO PRODUCE HYDROELECTRIC POWER IN $(0, T]$

$\mathrm{R}_{0}(\mathrm{t})=\mathrm{q}_{01}(\mathrm{t})[\mathrm{c}] \mathrm{R}_{1}(\mathrm{t})+\mathrm{q}_{02}(\mathrm{t})[\mathrm{c}] \mathrm{R}_{2}(\mathrm{t})$

$\mathrm{R}_{1}(\mathrm{t})=\mathrm{S}_{1}(\mathrm{t})+\mathrm{q}_{01}(\mathrm{t})[\mathrm{c}] \mathrm{R}_{1}(\mathrm{t})+\left[\mathrm{q}_{11}{ }^{(3)}(\mathrm{t})+\mathrm{q}_{11}{ }^{(4)}(\mathrm{t})[\mathrm{c}] \mathrm{R}_{1}(\mathrm{t})\right.$,

$\mathrm{R}_{2}(\mathrm{t})=\mathrm{q}_{20}(\mathrm{t})[\mathrm{c}] \mathrm{R}_{0}(\mathrm{t})+\left[\mathrm{q}_{22}{ }^{(6)}(\mathrm{t})+\mathrm{q}_{22}{ }^{(5)}(\mathrm{t})\right][\mathrm{c}] \mathrm{R}_{2}(\mathrm{t})$

Taking Laplace Transform of eq. (14-16) and solving for $\widehat{R_{0}}(s)$

$$
\widetilde{R_{0}}(s)=\mathrm{N}_{3}(\mathrm{~s}) / \mathrm{D}_{3}(\mathrm{~s})
$$

where

$\mathrm{N}_{3}(\mathrm{~s})=\hat{q}_{01}(\mathrm{~s}) \hat{S}_{1}(\mathrm{~s})$ and $\mathrm{D}_{3}(\mathrm{~s})=\left(1-\hat{q}_{11}{ }^{(3)}(\mathrm{s})-\hat{q}_{11}{ }^{(4)}(\mathrm{s})\right)-\hat{q}_{01}(\mathrm{~s})$ is already defined.

In the long run, $\mathrm{R}_{0}=\frac{N_{\mathrm{g}}(0)}{D_{\mathrm{z}}(0)}$

The expected period of the system under FH-failure resulting from Very low gravity in $(0, t]$ is $\lambda_{r v}(\mathrm{t})=\int_{0}^{\infty} R_{0}(z) d z$ So that $\widehat{\lambda_{r v}}(\mathrm{~s})=\frac{\widehat{\mathrm{R}}_{\mathrm{Q}}(\mathrm{s})}{\mathrm{g}}$

\section{THE EXPECTED BUSY PERIOD OF THE SERVER WHEN THERE IS HIGH ACOUSTICS IN} $(\mathbf{0}, \mathbf{T}]$

$\mathrm{B}_{0}(\mathrm{t})=\mathrm{q}_{01}(\mathrm{t})[\mathrm{c}] \mathrm{B}_{1}(\mathrm{t})+\mathrm{q}_{02}(\mathrm{t})[\mathrm{c}] \mathrm{B}_{2}(\mathrm{t})$

$\mathrm{B}_{1}(\mathrm{t})=\mathrm{q}_{01}(\mathrm{t})[\mathrm{c}] \mathrm{B}_{1}(\mathrm{t})+\left[\mathrm{q}_{11}{ }^{(3)}(\mathrm{t})+\mathrm{q}_{11}{ }^{(4)}(\mathrm{t})\right][\mathrm{c}] \mathrm{B}_{1}(\mathrm{t})$

$\mathrm{B}_{2}(\mathrm{t})=\mathrm{T}_{2}(\mathrm{t})+\mathrm{q}_{02}(\mathrm{t})[\mathrm{c}] \mathrm{B}_{2}(\mathrm{t})+\left[\mathrm{q}_{22}{ }^{(5)}(\mathrm{t})+\mathrm{q}_{22}{ }^{\left({ }^{6}\right)}(\mathrm{t})\right][\mathrm{c}] \mathrm{B}_{2}(\mathrm{t})$

$\mathrm{T}_{2}(\mathrm{t})=\mathrm{e}^{-\lambda}{ }_{1}^{\mathrm{t}} \mathrm{G}_{2}(\mathrm{t})$

Taking Laplace Transform of eq. (19-21) and solving for $\widehat{B_{0}}(s)$

$$
\widehat{B_{0}}(s) \quad=\mathrm{N}_{4}(\mathrm{~s}) / \mathrm{D}_{2}(\mathrm{~s})
$$

where

$\left.\mathrm{N}_{4}(\mathrm{~s})=\hat{q}_{02}(\mathrm{~s}) \widehat{T}_{2}(\mathrm{~s})\right)$ and $\mathrm{D}_{2}(\mathrm{~s})$ is already defined.

In steady state, $\mathrm{B}_{0}=\frac{N_{4}(0)}{D_{2}(0)}$

The expected busy period of the server for repair in $(0, t]$ is 


\section{ISSN: 2319-8753}

IJIRSET

\section{International Journal of Innovative Research in Science, Engineering and Technology}

(An ISO 3297: 2007 Certified Organization)

Vol. 3, Issue 10, October 2014

$\lambda_{r u}(\mathrm{t})=\int_{0}^{\infty} B_{0}(z) d z \quad$ So that $\widehat{\lambda}_{r u}(\mathrm{~s})=\frac{\widehat{\mathrm{B}}_{\mathrm{Q}}(\mathrm{s})}{\mathrm{s}}$

\section{THE EXPECTED NUMBER OF VISITS BY THE REPAIRMAN FOR REPAIRING THE NON- IDENTICAL UNITS IN $(0, T]$}

$\begin{aligned} \mathrm{H}_{0}(\mathrm{t}) & =\mathrm{Q}_{01}(\mathrm{t})[\mathrm{s}]\left[1+\mathrm{H}_{1}(\mathrm{t})\right]+\mathrm{Q}_{02}(\mathrm{t})[\mathrm{s}]\left[1+\mathrm{H}_{2}(\mathrm{t})\right] \\ \mathrm{H}_{1}(\mathrm{t}) & \left.=\mathrm{Q}_{10}(\mathrm{t})[\mathrm{s}] \mathrm{H}_{0}(\mathrm{t})\right]+\left[\mathrm{Q}_{11}{ }^{\left({ }^{3}\right)}(\mathrm{t})+\mathrm{Q}_{11}{ }^{(4)}(\mathrm{t})\right][\mathrm{s}] \mathrm{H}_{1}(\mathrm{t}), \\ \mathrm{H}_{2}(\mathrm{t}) & =\mathrm{Q}_{20}(\mathrm{t})[\mathrm{s}] \mathrm{H}_{0}(\mathrm{t})+\left[\mathrm{Q}_{22}{ }^{(5)}(\mathrm{t})+\mathrm{Q}_{22}{ }^{\left({ }^{6}\right)}(\mathrm{t})\right][\mathrm{c}] \mathrm{H}_{2}(\mathrm{t})\end{aligned}$

Taking Laplace Transform of eq. (25-27) and solving for $H_{0}^{8}(s)$

$$
H_{0}^{8}(s)=\mathrm{N}_{6}(\mathrm{~s}) / \mathrm{D}_{3}(\mathrm{~s})
$$

In the long run, $\mathrm{H}_{0}=\frac{N_{6}(0)}{D_{\mathrm{g}}(0)}$

\section{COST-BENEFIT ANALYSIS}

The Cost-Benefit analysis of the system considering mean up-time, expected busy period of the system under High acoustics when the units stops automatically, expected busy period of the server for repair of unit under nonavailability of water resulting not to produce Hydroelectric power, expected number of visits by the repairman for unit failure.

The expected total Benefit-Function incurred in $(0, t]$ is

$C(t)=$ Expected total revenue in $(0, t]$ - expected total repair cost in $(0, t]$ due to High acoustics failure

- expected total repair cost repairing the units in $(0, \mathrm{t}]$ due to FNAW: failure due to non-availability of water resulting not to produce hydroelectric power

- expected busy period of the system under High acoustics when the units automatically stop in $(0, t]$

- expected number of visits by the repairman for repairing of non-identical the units in $(0, t]$

The expected total cost per unit time in steady state is

$$
\begin{aligned}
\mathrm{C} & =\lim _{t \rightarrow \infty}(C(t) / t)=\lim _{s \rightarrow 0}\left(s^{2} C(s)\right) \\
& =\mathrm{K}_{1} \mathrm{~A}_{0}-\mathrm{K}_{2} \mathrm{R}_{0}-\mathrm{K}_{3} \mathrm{~B}_{0}-\mathrm{K}_{4} \mathrm{H}_{0}
\end{aligned}
$$

where

$\mathrm{K}_{1}$ - revenue per unit up-time,

$\mathrm{K}_{2}$ - cost per unit time for which the system is under repair of type- I

$\mathrm{K}_{3}$ - cost per unit time for which the system is under repair of type-II

$\mathrm{K}_{4}$ - cost per visit by the repairman for units repair.

\section{CONCLUSION}

After studying the system, we have analyzed graphically that when the failure rate due to non-availability of water resulting not to produce hydroelectric power and failure rate due to High acoustics increases, the MTSF and steady state availability decreases and the Cost-Benefit function decreased as the failure increases.

\section{REFERENCES}

[1] Dhillon, B.S. and Natesen, J, Stochastic Anaysis of outdoor Power Systems in fluctuating environment, Microelectron. Reliab.;23, 867-881.1983.

[2] Kan, Cheng, Reliability analysis of a system in a randomly changing environment, Acta Math. Appl. Sin., 2, pp.219-228, 1985.

[3] Cao, Jinhua, Stochatic Behaviour of a Man Machine System operating under changing environment subject to a Markov Process with two states, Microelectron. Reliab. , 28, pp. 373-378, 1989.

[4 Barlow, R.E. and Proschan, F., Mathematical theory of Reliability, John Wiley, New York, 1965.

[5] Gnedanke, B.V., Belyayar, Yu.K. and Soloyer, A.D., Mathematical Methods of Reliability Theory, Academic Press, New York, 1969. 